University of Wollongong

Research Online

Faculty of Law, Humanities and the Arts Papers (Archive)

$1-1-2018$

Experiences of parents who support a family member with intellectual disability and challenging behaviour: "This is what I deal with every single day"

Shoshana J. Dreyfus

University of Wollongong, shooshi@uow.edu.au

Leanne Dowse

University of New South Wales

Follow this and additional works at: https://ro.uow.edu.au/lhapapers

Part of the Arts and Humanities Commons, and the Law Commons

Research Online is the open access institutional repository for the University of Wollongong. For further information contact the UOW Library: research-pubs@uow.edu.au 


\title{
Experiences of parents who support a family member with intellectual disability and challenging behaviour: "This is what I deal with every single day"
}

\author{
Abstract \\ Background: Research into parents' experiences of living with a family member with intellectual disability \\ and challenging behaviour does not specifically address what parents say about themselves and their \\ lives. This paper explores "I-statements" parents made about their day-today actions in life with their \\ family member. \\ Methods: Semi-structured interviews were conducted with 26 parents, of which $91 \%$ were mothers. "I- \\ statements" were analysed using process analysis from systemic functional linguistics and thematic \\ analysis. \\ Results: "I-statements" showed that parents enacted a range of complex and sometimes extreme \\ activities across a variety of life domains. Parents spoke about: managing relationships with services; \\ educating themselves and others; seeking support; resisting poor service delivery; assisting others; and \\ making both small and significant changes. \\ Conclusion: The paper provided insights into the complex lives of these families and offered observations \\ on the implications of the potential misalignment between the supports the data suggests are needed \\ and those that, in reality, are available to them.

\section{Disciplines} \\ Arts and Humanities | Law

\section{Publication Details} \\ Dreyfus, S. \& Dowse, L. (2018). Experiences of parents who support a family member with intellectual \\ disability and challenging behaviour: "This is what I deal with every single day". Journal of Intellectual and \\ Developmental Disability, Online First 1-11.
}


Published as: Dreyfus, S. \& Dowse, L. (2018). Experiences of parents who support a family member with intellectual disability and challenging behaviour: "This is what I deal with every single day". Journal of Intellectual and Developmental Disability, Online First 1-11. doi: $10.3109 / 13668250.2018 .1510117$

"This is what I deal with every single day": What 'I-statements' can tell us about the lives of parents who support a family member with intellectual disability and challenging behaviour

Dr Shoshana Dreyfus

School of Humanities and Social Inquiry, University of Wollongong, Wollongong, Australia

Corrseponding author's address:

School of Humanities and Social Inquiry, Faculty of Law, Humanities and the Arts, University of Wollongong, Wollongong, 2500 Australia

Corrseponding author's email: $\underline{\text { shooshi@uow.edu.au }}$

Professor Leanne Dowse

School of Social Sciences, University of New South Wales, Sydney, Australia

\begin{abstract}
Background: Research into parents' experiences of living with a family member with intellectual disability and challenging behaviour does not specifically address what parents say about themselves and their lives. This paper explores "I-statements" parents made about their day-to-day actions in life with their family member.
\end{abstract}

Methods: Semi-structured interviews were conducted with 26 parents, of which $91 \%$ were mothers. "I-statements" were analysed using process analysis from systemic functional linguistics and thematic analysis. 
Results: "I-statements" show: parents enacted a range of complex and sometimes extreme activities across a variety of life domains. Parents spoke about: managing relationships with services; educating themselves and others; seeking support; resisting poor service delivery; assisting others; and making both small and significant changes.

Conclusion: The paper provides insights into the complex lives of these families and offers observations on the implications of the potential misalignment between the supports the data suggests are needed and those that, in reality, are available to families.

Keywords: intellectual disability and challenging behaviour, families, caring for a family member with disability

\section{Introduction}

Families with a member with intellectual disability and challenging behaviour ${ }^{1}$ typically face a range of challenges that can include interpersonal violence, destruction of their home and environment, sleep deprivation, high levels of depression and stress, lower quality of life generally and social isolation (Biswas, Moghaddam \& Tickle, 2015; Duignan \& Connell, 2015; Griffith and Hastings, 2014; Hubert, 2010; Maes, Broekman, Došen \& Nauts 2003; Ng \& Rhodes, 2018). These families often rely on the assistance of a behaviour support specialist in order to help them meet their family member's behaviour support needs, however in Australia, there is no research into these families' specific contexts. With the service landscape now rapidly transforming under the influence of the National Disability Insurance Scheme (NDIS), a wholesale shift from bulk funding of services to person-centred care and individualised budgets, support that

\footnotetext{
${ }^{1}$ We acknowledge that the language used to define behaviour and behaviour supports is contested and varies internationally. In this paper we use 'challenging behaviour' as the predominant term used in peer-reviewed literature and by the study informants to refer to behaviour that places people with disability and/or others at significant risk of harm. We recognise that behaviours may pose challenges to individuals, their supporters and the services and systems in which they are embedded.
} 
families themselves provide is increasing relegated to the 'informal' sphere, obscuring the need to address supports needed by those very families. This paper seeks to make visible the lives families lead whilst living with and caring for a family member with intellectual disability and challenging behaviour, to ensure that service capacity to support them remains in focus.

Within the research addressing family experiences of caring for a family member with a disability (see for example Cummins, 200; McConkey, 2005; McKenzie, Mayer, Whelan, McNall, Noone \& Chaplin, 2017; Plant \& Sanders, 2007; Storr, 2014; Thompson-Janes, Brice, McElroy, Abbott \& Ball, 2014) a small subset of studies focuses on the experiences of families whose family member not only has intellectual disability but also challenging behaviour (see for example Hatton, Emerson, Kirby, Kotwal, Baines, Hutchinson, Dobson \& Marks, 2010; Maes, Broekman, Došen, \& Nauts, 2003; McGill, Tennyson, \& Cooper, 2005; McGill, Papachristoforou, \& Cooper, 2006). While a number of these studies identify the challenges and strains of these families, few show the detail of what family members do on a day-to-day basis to navigate their lives.

Duignan and Connell's (2015) study utilising surveys examines how caring for people with autism spectrum disorder (and challenging behaviour) impacts the activities of family carers and their experiences of home. In particular, the study looked at how the care changes family relationships, attitudes to domestic space and the nature of home, and found that the impact was "predominantly negative" (p208). Providing people with autism with the least restricted life possible in the family home was found to make for a most restricted life for the families, particularly when it came to social and physical relationships. This, in turn, resulted in a reduced quality of life, a change in patterns of 
behaviour, exclusion from some of the "normal" activities that other families engage in, and in some cases, avoidance of the home altogether. While this study is survey-based and focuses on people with autism, it is one of the few that begins to unpack the lives of families who live with and care for a member with challenging behaviour.

Thompson-Janes, et al's (2014) study focused on parents' experiences of attending a therapeutic group for parents of children with learning disabilities and challenging behaviour. The study confirmed the findings of previous studies that group interventions are beneficial for the wellbeing of parents that fall into this category.

Griffith and Hastings (2013) conducted a synthesis of 17 qualitative studies on the perspectives of those caring for a family member with intellectual disability and challenging behaviour, with a focus on carers' experiences of support services. Conclusions included that while carers spoke of a deep love for their family member, they also spoke of the chronic strain placed upon them by their caring role and described their lives as a "fine balancing act" (p411) of juggling care needs, challenging behaviour episodes, issues with support services and setting up services for the future. Hubert's (2010) two-year examination of mothers' perspectives of life with a young person who has intellectual disability and challenging behaviour found that most mothers were socially isolated, even from close relatives, but that despite this, most were determined not to place their child into institutional care for fears about their safety and wellbeing, even though keeping them at home meant life was difficult. Drysdale, Jahoda and Campbell's (2009) study of mothers' "attributions" of their family member's self-injurious behaviour examined what mothers said about their child's challenging behaviour, finding that these attributions were a strong predictor of maternal well-being. 
More recently, McKenzie et al (2017) explored the experiences of family carers in the UK who have an adult member with intellectual disability who received a behaviour support service that was deemed to be positive. Using both focus group and interview methods with eight family carers, this study specifically focused on the behaviour support service families had received, and does highlight important issues in its subthemes, such as emotional challenges, and the tensions that can arise between the family and professionals.

A number of studies have considered issues to do with relinquishment of a family member with intellectual disability and behaviour support needs. Ng and Rhodes (2018) interviewed disability professionals who work with families who have relinquished care in the state of New South Wales, Australia, in order to understand the factors that lead to relinquishment. The findings included that almost all the people relinquished had extreme challenging behaviours and that it was physical aggression towards the mother and siblings that was seen to be a major factor for families. However, it was a complex mix of factors including social isolation, marital stress (if still in such a partnership) and financial stress, and lack of support generally that contributed to the relinquishment. While, $\mathrm{Ng}$ and Rhodes state clearly that they are not representing the views of families in their study, they do articulate important points around the need for further research that investigate the lives of families in this position, to better understand the pressures that lead to relinquishment.

To date, methodologically, the studies that have considered parents' experiences of their family member with intellectual disability and challenging behaviour have relied on 
qualitative thematic analysis to draw out general observations about that experience. Whilst valuable in producing knowledge about the lives of families caring for a member with intellectual disability and challenging behaviour, this body of work has not addressed with any specificity what parents 'do' to negotiate the complexities and demands of this life. Our study fleshes out this space by examining in detail parents' talk about themselves and their lives in context, to help better understand the demands on the lives of parent carers.

\section{Research Design and Method}

This study utilises a thematic analysis as well as tools of analysis from a systemic functional linguistic framework (Halliday and Matthiessen, 2014), which views language as a complex form of social behaviour, to analyse language from parent interviews, drawn from a broader study investigating the experience of parents across Australia who have a family member with intellectual disability and challenging behaviour in receiving a behaviour support service. These data are reported in greater detail elsewhere (Dowse, Hogan, Dew, Wiese, Conway, Dreyfus and Smith 2017).

This paper focuses on a subset of the broader data, specifically the "I-statements" parents made in interviews, to illuminate the range of activities they undertake in the context of their lives with their family member.

Ethical approval was given for the study by the University of New South Wales' Human Research Ethics Committee. In recognition of the potentially distressing nature of the subject matter, care was taken to provide a protocol for an independent counselling service to be made available for participants. 


\section{Recruitment and participants}

Families were recruited to the study via a range of methods including callouts on popular Australian disability Facebook pages, via disability organisation newsletters, and via researcher networks. In total, 26 families were interviewed across the states of New South Wales, Western Australia, Queensland and South Australia in 2016. Demographic characteristics for 'situating' the sample (Elliott et al, 1999) were gathered from interviewees against a range of indicators including geographic location, gender, family role and language background together with characteristics of their family member with behaviour support needs. Participants were almost evenly spread between metropolitan areas (41\%) and regional areas (54\%), with one location unknown. The vast majority of informants (95\%) were parents, with one grandparent carer, and a strong predominance of females mothers (91\%). Although two fathers were also present at interviews, in these two cases, the mothers did most of the talking. While it is clear from this data set that mothers often take up the main parenting and managing role in these families, the term "parents" will be used to describe the group, to account for the small number of fathers interviewed. All were from an English-speaking background.

The profile of family members with behaviour support needs in the interviewees' care included an age range of 4-36 years, with an average age of 23 years and a majority $(75 \%)$ of males. Parents were asked about the characteristics of their family member, with $91 \%$ reported as being on psychotropic medication for help with their behaviour, $79 \%$ had complex communication needs and many exhibited violent behaviours, with 54\% self-harming, $78 \%$ harming others and $62 \%$ harming their environment. Four families were already in the NDIS, meaning they were being serviced by the national 
consumer-directed, individualised budget model rather than by a block funded service provision model.

\section{Data collection}

Semi-structured interviews were used to explore the families' experience of seeking and receiving behaviour support services for their family member. Interview questions focused on aspects of behaviour support services received, including the extent to which behaviour support needs were met, whether the service and the person who provided it were responsive or not, and whether the service made a difference or not. Interviews were conducted face-to-face where possible or via an online meeting platform. All interviews were audio recorded with the consent of participants and were transcribed verbatim.

\section{Data analysis}

The data were first analysed with an aspect of systemic functional linguistic (SFL) tools of analysis called process type analysis. SFL has been used to explore many facets of language. Process type analysis involves classifying clauses according to the type of verbal group that forms the process. There are five different process types (Halliday \& Matthiessen 2014), reflecting different kinds of events and states of being. These are as follows:

1) material - which are prototypical actions, e.g. walk, get (something);

2) behavioural - actions engaged in by sentient beings, e.g. cough;

3) mental - processes of cognition, perception and reaction, e.g. think, see, feel;

4) verbal - processes of expression, e.g. say, ask; and

5) relational - processes of being and having, e.g. is/are, have. 
This type of analysis has been used to examine a diversity of objects of study including literature (eg Martin, 2000), and the discourse of war (eg Lukin, 2013). It has also been deployed on participants' talk in interviews to explore the grammatical choices patients make to describe themselves in, for example, advanced cancer treatment (Karimi et al., in press) and psychotherapy sessions (Henderson-Brooks 2006). This type of analysis rests on the assumption that what people do or experience is made visible in the way they talk about their lives, and therefore investigating this talk can make visible different aspects of human experience as constructed in and by language.

Data for the broader study were initially analysed thematically, however during this analysis the researchers noted that in responding to the questions about behaviour support, parents talked a lot about what they do in their lives with their family member and thus uttered many "I-statements", that is, statements where they begin a sentence with "I" and follow this with some kind of "action", such as: I decided to move from Adelaide to Sydney in 1995. Given what is known about the poorer health and mental health outcomes of parents who care for a son or daughter with intellectual disability and challenging behaviour, we observed that these statements provided access to a range of specific actions parents take which are seldom explored in the research literature. These I-statements were collected from the broader data, as a specific subset in order to make visible the actions and activities expressed by parents.

Parents uttered a total of 3508 I-statements, however those related to reported speech (ie. reporting on a conversation they had had with someone), emotions, idioms and comments relating to the interview itself were excluded, leaving 1376 I-statements. 
The process analysis allowed us to easily identify the material processes ${ }^{2}$, that is, what parents said they $d o(n=126)$. These were then selected for analysis. These data have the potential to yield detailed information about the different kinds of things parents $d o$ in relation to behaviour support and life with a person with intellectual disability and challenging behaviour. Figure 1 below sets out the process of selection of the final dataset of positive I-statements utilised in the study.

Figure 1 here

The material processes were then further classified thematically, according to the different categories of things parents said they did, creating a picture of their lives as talked about in these interviews.

\section{Results}

Interrogating the material processes that parents said they do revealed that they primarily talked about taking actions relating to themselves and their family member, and to others including their peers, their service providers and their systemic or political context. These actions clustered into seven six main areas, shown in Figure 2, from most to least frequent, which we have identified as related to management, education, support seeking, resistance, assistance and change.

Figure 2 here

Table 1 shows the numbers of instances across these categories:

\footnotetext{
${ }^{2}$ As is sometimes common in linguistic analysis, behavioural processes were subsumed into the category of material.
} 
Table 1 here

\section{I manage...}

The most frequent set of activities parents spoke of was in relation to the management of the many aspects of life with a person with intellectual disability and challenging behaviour, that is, management of finances, funding packages, their family member's behaviour, the behaviour support process and their day-to-day life with their family member, as per Figure 3:

Figure 3 here

The most frequent category of management that parents spoke about pertained to the wide range of tasks that accrue in managing their day-to-day life with their family member. These include many mundane, repetitive administrative and organising activities that are foundational to the smooth running of their family member's program of health, social care and support. Importantly in the seven domains of activity, as seen in Figure 3.1, parents even identified 'waiting' as a key in/activity related to their management of day-to-day life.

Figure 3.1 here 
The activities and tasks parent spoke of in managing day-to-day life with their person cluster around 11 types. Four of the five most frequent are very closely related, with making phone calls the most frequent of these. For example:

So when I started to have trouble again and would call back and say "I need some help, what do I do?", they'd go, "We can't help you”.

However the making of phone calls is somewhat masked, as many of the next most frequent activities in this set also involved phone contact, though parents didn't necessarily speak about that in these instances. Closely linked to making phone calls and following close behind in frequency is organising and attending appointments with a range of people such as doctors, school teachers, counsellors, psychologists, speech therapists, occupational therapists, and in some cases, the police. The following example show's a mother detailing the frequent behaviour support meetings she and her husband attended:

\section{Both my husband and I attended [behaviour support meetings] each week, there might have been one week where we didn't because of school holidays or something but generally it was two hours every week for nine months.}

The next most frequent and related activities parents spoke of managing are relationships with agencies such as schools, hospitals, disability departments and services, and interacting with many people in both these formal and other informal contexts. Families specifically spoke about needing to manage their behaviour support service in order to "keep it on track". These processes were summed up by one 
participant as a 'roundabout', which can be experienced as 'overwhelming' when taken together with the need to attend to normative family functions:

...in the days when we were dealing with all that service provision, you know, that roundabout that you are on. I used to show them my calendar. I used to hold it up to them and go, "Look. Look. This is what I deal with every single day. This is how many phone calls I have made today. This is who I spoke to today." And I once drew a map: doctor, specialist, psychologist, psychiatrist, day program, blah blah. I said, "This is the number of people I am dealing with every day as well as trying to get the meal on the table." It is so overwhelming.

Parents who self-managed their social care packages also identified the constant and ongoing pressure involved in securing support workers to work with their family member, and that this was an ongoing struggle, as one participant explained:

Identifying them, recruiting them and keeping them is just, a constant, constant battle.

A further area of managing day-to-day life related to administrative tasks such as filling in forms. Some parents articulated this as a very onerous and repetitive task, particularly so for those who moved or changed services, where each new service required them to fill in more forms, as this mother details: 


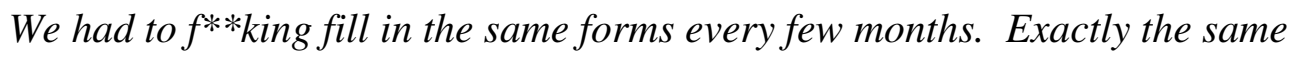
forms. They didn't even have a database. I spent my life filling in forms. So, lucky I'm okay with forms and they're not a struggle. If they were a struggle, I would have spent half my life filling in forms. I used to show people my calendar and tell people how many forms I filled in, how many calls I made, how and much planning I had to do for B's life. It took up a quarter of my life, on top of the care.

Importantly parents also identified 'waiting' as a common characteristic of their day-today management. On face value it might be assumed that waiting signals the absence of activity, as inactivity, but for parents in this study, who spoke of waiting to hear back from commissioning bodies, services and practitioners sometimes for very long periods, this absence of action on the part of others was perceived as an active and particularly frustrating aspect of their day-to-day lives, eg:

Once he was diagnosed, it was a whole year and we had heard nothing. Apparently they filed his information and it was just left in a drawer. We received no help with the diagnosis in 2010, 2011, somewhere around there. I waited the year and then I rang up.

Parents spoke about managing the modifications and repairs they frequently needed to make to their home environments to cope with the day-to-day living with their family member, if and when their family member acted out on the home environment. Modifications included placing locks on doors and cupboards, replacing glass, walls and furniture, eg: 
There's smashed doors in the house... I've had to put felt on the doors because when he slams the doors the glass smashes, because we've got French doors, and all that sort of thing. If he's got a temper, he'll just kick a door in or he'll smash anything.

These same actions were also applied to the need to make modifications to the other environments in which their family member attended, such as school and preschool, as captured in this example:

There was a fish tank at the preschool, so he'd go and stick his hands in the fish tank and jiggle all the water around. Of course, he can't do that, so my partner, his dad, had to build a lid for the fish tank.

Parents spoke of managing their finances. Having a family member with a disability and challenging behaviour can increase the financial stress on a family (Doran et al., 2012), sometimes because of the disability and sometimes because of the challenging behaviour. Here, parents talked about the extra costs for doctors, allied health professionals, and for some, repair of environmental damage to the family home. In managing finances, parents also spoke of stretching the funding they were allocated, paying for services and setting aside money for special equipment, as this mother explains:

I just had that broken down. That is just over $\$ 15,000$, close to $\$ 16,000$ on the ABA therapy. It's somewhere around \$9,000 for the psych. You've got between 
$\$ 6,000$ to $\$ 7,000$ for the OT and physio, and then you've got the speech therapy. They've covered \$2,000 of that and ourselves, we'll cover $\$ 2,700$ of that. Then you've got the extra things, like the assisted technology, the incontinence and, what else was the last one, orthotics and stuff like that.

Linked to the issue of financial management, parents also identified the related issue of managing social care resources allocated to their family member via their formal funding packages. This included organising and coordinating the care and support, recruiting workers and paying invoices. This kind of management was identified as key to the choice and control they have over who provides the funded supports, for example, as one mother stated: I self-manage my NDIS funding so I get to choose who my providers are.

Parents spoke frequently, in one way or another, about managing their family member's behaviour, some at all hours and most in all settings, as this mother describes when trying to decipher why her son hit himself:

I was giving him something to eat and then he went and hit himself. I backed off and I didn't know what it was about. Then when I went to try and give him it again he got really cranky and he bit himself. I think maybe it was that he didn't like what I was feeding him but he can't say that so he's going display a behaviour...

Relatedly, when behaviour support services were provided to their family member, rather than identifying this service as a relief in their management roles since it may be 
overseen by professionals, parents spoke about an additional need to coordinate the multiple professionals across multiple settings in order to keep it on track, oversee it and make sure that it is applied in various settings, as one parent mother commented:

Childcare centres, Montessori schools, things like that, would have a look at her and then say no, no, no. We did auditory integration training. I tried all the ABA. I cannot remember who was actually helping me - I was coordinating everything anyway

Interestingly, while parents identify themselves in this role as manager of their family member's behaviour support intervention, this type of involvement is seldom recognised in the scholarly and grey literature on behaviour support, which predominantly constructs parents as a stakeholder in implementing behaviour support strategies in the home and community (see for example Keen, 2007; Dunlap \& Fox, 2007).

2. I educate myself...

The second most frequent set of activities parents spoke about undertaking (as per Figure 2) relates to educating themselves. Some spoke of formal education as a key material action they take, as one mother explained:

I did a Master of Education in emotional intelligence. A bit of a game changer actually. Really helped a lot. 
and most Many also mentioned informally accessing information via online platforms. Education in formal settings included a range of undergraduate and postgraduate programs at universities, and training courses offered by organisations providing specific instruction relating to either challenging behaviour or other matters to do with disability and parenting. Courses included Master of Education, Positive Parenting Program (Triple P), Pragmatically Organised Dynamic Display (PODD) training, Augmentative and Alternative Communication (AAC) training, Auditory Integration training, Applied Behavioural Analysis (ABA) therapist training, human resources and occupational health and safety, and sign language training. In the context of their education activities some parents also conducted formal research in university-based programs of study. This mother said:

I did my PhD on his communication. I'm a linguist by training and I used a linguistic framework to try and map his non-verbal communication system. I did a Master of Education in emotional intelligence. A bit of a game changer actually. Really helped a lot.

Parents also identified educating themselves in an informal sense via various digital platforms and on the internet generally, as one mother indicated:

Jack was diagnosed at age two when we were living in Newcastle, and I think within a couple of weeks or even a month I googled, worked out that we wanted to do early intensive behavioural intervention. 


\section{I seek support...}

Support seeking was the third most frequently spoken about set of activities in the data set. Here, parents identified their actions in pursuing assistance for their family member with challenging behaviour as well as for themselves. Specifically, they spoke of engaging an advocate, sourcing respite care, gaining a placement in a pre-school, school or program, getting other people involved in their family member's life, employing workers and connecting with services. The following example shows one mother's actions to get support through respite:

I got him into respite really young so he was around that environment. I think I must have just needed that time away to deal with it.

\section{I resist...}

Many parents found themselves in the position of receiving less than satisfactory support services for their family member. Addressing this required them to take action to demand accountability and redress by professionals, services or systems. This was the fourth most frequent set of activities parents spoke of doing and was construed by many as 'fighting back' or 'resisting'. Actions here took the form of sending reports back, asking for internal and external reviews, writing letters to Ministers and local members of Parliament, and in one instance, taking legal action against a commissioning body. Parents noted that while these actions were not something they would choose to do, they felt forced into a position of resistance because of successive 
and cumulative poor experiences which led to the need for increasing escalation in their response to those from whom they expected support, as one mother detailed:

If, when I first started, they had given me \$16,000 to start with, I would have backed right the hell off not knowing any better and buggered off but the more they kept saying no to me and "you can't" and "we don't know" and "we've given you another planner", “don't ring us or email us", "your planner is this", "Who the $f .$. is that?" "That's your planner. Get a hold of your planner, don't talk to us." I was sent around so much that I thought, you know what, I might as well learn this crap because it sounds like I'm going to be here a while. So I started learning it and the more I learnt, the more I realised, you know what? 16,000 , I'm not happy with that. I went from $\$ 16,000$ to $\$ 42,000$ and then up to $\$ 58,000$ and I think by the time it's finished, I should be about $\$ 75,000$.

These actions also show that particular parents had a great deal of resilience and capacity to confront the processes and systems they saw as sub-standard or as giving them a bad deal. Many families, however, did not speak about these types of actions.

\section{I assist...}

In a small number of instances in the data, parents spoke about assisting others in similar circumstances. Two distinct groups were mentioned as the target of their assistance: peers and workers, and as shown in Figure 4, the kind of help they provided to each of these differed. 
Figure 4 here

Peer support activities for the families in this study occurred on a continuum, with some involved in formal programs and included them giving talks to groups of parents beginning to navigate the service system or acting as a formal mentor:

I think the peer support group that I belong to, the Side By Side program which is families that experience challenging behaviour supporting other families that experience challenging behaviour, I really think that that has been a huge benefit, not so much to my husband because he's not really involved as much as I am but for me, personally I can say that for me it's been almost liberating being able to speak openly and honestly or asking for advice or sharing ideas, that's been really beneficial.

More informal peer support activities included helping other families fill in funding applications. Parents also spoke about providing assistance to workers, both incidentally through instruction in situ to enhance workers' skills in supporting their family member, and more formally, in training workers in day programs and residential care to better understand, communicate with and engage with their family member. As one mother explains:

I now train the workers. I train his house workers every few months. I train his day program workers. I go in there with all my Powerpoints. I'm the behaviour support person now, and I've mapped his whole communication 
system about what means of expressions he uses to bond with people when he can't talk. So, I've got this whole system. I'm it now.

These actions on the part of parents point to the capacity that many develop over time to provide crucial systemic resources within the broader social care system.

\section{I change...}

Parents also talked about making changes to their lives in order to better be able to manage life with their family member. For many these were momentous changes such as moving location or changing their employment, as well as what might be seen as relatively small changes to the ways they live their day-to-day lives, but which nonetheless were of significance to their perceived quality of life. These are set out in Figure 5:

Figure 5 here

Many respondents talked about their decision to relocate their family to gain access to services that would better support their family member, the behaviour and their lives. The general pattern of this movement is characterised by shifts toward more populous and urban areas, such as from rural to regional areas and from towns in regional areas to cities. Others Three mothers reported moving from one city to another if services were perceived to be better or more easily accessed elsewhere, and one family relocated overseas to find more appropriate services and support: 
Then we packed up and moved to England and the expectation there was that we would be able to access some more intensive support services in England. Frankly, they were there but the process of convincing a local education authority that what you needed for your child was such a degree of investment, was quite challenging as well. Things pretty much went from bad to worse for me and then we came back to Australia.

Changes parents made to what they do also include quitting their job in order to be more available to support their child in the absence of adequate formal support, to better manage their lives, or to take up study.

In about 2012, A came here for four nights a week then and in 2013 she moved to live with me and L full time and I haven't worked since then.

Other changes parents spoke of making to how they live their lives included giving up on a full night's sleep as a result of getting up through the night, changing meal planning and preparing meals they would not normally find appetising, and changing their patterns of movement around the physical and social spaces of their communities. While taken individually, these changes may not appear to constitute particular hardship, however cumulatively they put enormous pressure on families:

It was very repetitive and I put all my time into him, but his schooling doesn't get done during schooling hours. He would mainly do it between midnight and 3:00am. No one is going to come out at that time to help him, so that's why we did it. When he woke me up, it didn't matter whether I had a migraine, you'd get 
up and you'd do the schoolwork with him because I didn't know if he'd do it tomorrow. It doesn't matter what was going on for us.

\section{Discussion}

Parents whose family includes a member with intellectual disability and behaviour support needs negotiate a complex array of material processes to manage and sustain themselves, their family and others in their networks. It should be noted that the study taps a small number of Australian families who have a member with intellectual disability and challenging behaviour and so findings should be extrapolated with caution. The initial target of 50 families for inclusion in the study was unable to be achieved and this we think reflects the importance of the work itself. Despite significant efforts to recruit on a national scale and within forums where families may be expected to be found, ultimately response rates were less than expected, likely reflecting the pressures and priorities of families who are already stretched in managing their day-today lives. Ultimately those families who did participate were recruited via small active peer networks. In addition, some of those who did express interest in participating were ultimately unable to commit time to a research interview because they were unable to find alternate care for their family member. In addition, the sample for the study does not include a diversity of families, including, for example, Aboriginal families and those from culturally and linguistically diverse backgrounds and thus is skewed towards native speakers of English. This limitation begs the call for research into the experiences of a range of diverse families.

The work reported here then represents a small exploratory study which seeks to begin to lay the foundations for a more sustained engagement with issues and experiences of 
families who have a member with intellectual disability and challenging behaviour. The processes identified by parents in the study traverse a spectrum from the mundane to the extraordinary, which when taken together, paint a picture of intense demand for both proactive and reactive activities that span the systemic, service and personal aspects of their lives.

Families are exposed to significant demands in relation to systems navigation, where they undertake a myriad of processes to ensure sufficient resource allocation for their family member's social care packages. In the move to personalisation in Australia, currently centred on the implementation of the NDIS, this is a burgeoning area of activity to the extent that parents are increasingly required to lead processes associated with eligibility and access to support schemes, planning of social care packages, identifying appropriate providers and most importantly, managing the fallout from ineffective or constrained allocations which are insufficient to meet their family member's support needs. This is particularly so in relation to the recognition that behaviour support requires an integrated approach across various systems and contexts which requires processes of communication and coordination that may not be recognised or performed by any one system, leaving parents as default care coordinators. Parents in this study particularly identified the temporal dimensions of this work, where many spoke of hours spent on the phone, in administrative tasks such as form filling and in states of 'waiting' for systemic processes and responses to occur. Importantly, some parents spoke of the further time and effort required to resist or 'fight-back' when systems fail them and their family member. As Walmsely et al. (2017, p1367) have recently observed in the UK context, 'advocacy is a daily task, for most families with relatives with learning disabilities, most of the time'. While little is 
yet known in Australia about the impact of the wholesale move to personalisation of social care services on the parents and families of people with intellectual disability who have challenging behaviour, the capacity of personalised systems to consider and address the interconnected nature of support for well-being of all family members is yet to be demonstrated. This added responsibility on parents, mostly mothers, to be both care-coordinators and advocates is construed as 'informal support' by schemes such as the NDIS, a term that implies supports that are unofficial, casual or natural, and most importantly, unpaid. The talk of parents in this study demonstrates that this is, at the very least, a misnomer that obscures the often totalising impact of these processes on families and, at its most pernicious, a discourse that de-authorises and erases recognition of the additional labour of parents, mostly mothers, of people with intellectual disability who have behaviour support needs.

In relation to processes associated with services for their family member with intellectual disability and challenging behaviour, parents in the study spoke of the demands of sourcing, collaborating on and monitoring the appropriateness and quality of services. Parents identified an almost bewildering array of service types, associated professionals and support practices related to their family which require their attention, and many noted the challenges they face in operating and bringing about change in these settings. There is significant literature which corroborates the experiences of the parents in this study, demonstrating that parents and professionals often have difficulty overcoming longstanding power differentials that undermine the position of parents as experts on their own child (Hodge \& Runswick-Cole, 2008). Parents often find themselves "acting in a semi-professional capacity, even when this is not a role they aspire to" (p640). Efforts on the part of parents to maintain these working relationships 
have been recognised as requiring significant emotional energy, particularly associated with masking their frustration at long delays and poor practice (Egilson, 2011) and as a source of significant stress (Read, 2000).

Many parents demonstrated high level expertise in the support approaches their family member required and their talk about their contributions of expertise and capacity building for particularly direct support workers and their peers was striking. That many services and professionals may underestimate or discount parental expertise is a significant missed opportunity, as is keeping parents tied up with the mundane juggle and frustration of their individual poor service experiences. The increasingly marketised context of social care provision represents both opportunity and risk for provider-parent co-production of services. While allocations of funding against particular forms of need such as behaviour support may be increasingly constrained, there is also opportunity to harness parental capacity for innovation in relation to, for example, peer-support as a model of support for other families. These newer approaches require a more flexible commissioning framework that transcends individual professional-parent partnerships, and which recognises and harnesses parents' expertise. Our research suggests that these may have significant potential to improve the experience of families who have a member with challenging behaviour.

At a personal level parents spoke about the range of actions they undertake in managing their lives and those of their families. These ranged from small, incidental and repetitive to the far-reaching, such as career changes, undertaking education and taking lifechanging actions, such as moving their family to another town, state or country in search of better solutions. But what stands out most in this research is the cumulative 
effect of all these different actions, which occur on top of normative family lives.

Nonetheless, some families importantly spoke of their personal commitment to assisting their peers and to fighting the system when it did not work for them or their family member, showing resilience and capacity in the face of extraordinary circumstances. The hope for this paper is that if we are able to make visible the lives of these families, policy makers will be more open to providing a system that supports not only the person with disability but their families who support them.

Acknowledgements: We acknowledge the families who gave of their precious time to be interviewed for this study. This work was supported by funding from the NSW Department of Family and Community Services.

\section{References}

Biswas, S., Moghaddam, N. \& Tickle, A. (2015). What are the factors that influence parental stress when caring for a child with an intellectual disability? A critical literature review. International Journal of Developmental Disabilities, 6(3), 127146.

Cummins, R.A. (2001). The subjective well-being of people caring for a family member with a severe disability at home: a review. Journal of Intellectual \& Developmental Disability 26(1), 83-100.

Doran, C.M., Einfeld, S.L., Madden, R.H., Otim, M., Horstead, S.K., Ellis, L.A. \& Emerson, E. (2012). How much does intellectual disability really cost? First 
estimates for Australia. Journal of Intellectual \& Developmental Disability, $37(1), 42-49$.

Dowse, L., Hogan, L., Dew, A., Wiese, M., Conway, P., Dreyfus, S., \& Smith, L. (2017). Responding to Behaviour Needs in the Disability Services Future, Discussion Paper. Sydney: UNSW Sydney.

Drysdale, E.E., Jahoda, A. \& Campbell, E. (2009). Investigating Spontaneous Attributions in Mothers of Individuals with Intellectual Disabilities and SelfInjurious Behaviour British Journal of Learning Disabilities, 37(3), 197-206 Sep

Duignan, M. and J. Connell (2015). "Living with Autistic Spectrum Disorders: Families, Homes and the Disruption of Space." Geographical Research, 53(2), 199-210.

Dunlap, G. and Fox, L. (2007) Parent-professional partnerships: A valuable context for addressing challenging behaviours, International Journal of Disability, Development and Education, 54(3), 273-285.

Egilson, S. T. (2011). Parent perspectives of therapy services for their children with physical disabilities. Scand J Caring Sci, 25(2), 277-284.

Elliott, R., Fischer, C.T. \& Rennie, D. L. (1999) Evolving guidelines for publication of qualitative research studies in psychology and related fields. British Journal of Clinical Psychology, 38, 215-219.

Griffith, G.M. \& Hastings, R.P. (2014). 'He's hard work, but he's worth it'. The Experience of Caregivers of Individuals with Intellectual Disabilities and Challenging Behaviour: A Meta-Synthesis of Qualitative Research. Journal of Applied Research in Intellectual Disabilities 27(5), 401-419. 
Halliday, M.A.K. \& Matthiessen, C.M.I.M (2014). Halliday's Introduction to Functional Grammar ( $4^{\text {th }}$ ed). London \& New York: Routledge.

Hasan, R. (1985) Linguistics, language and verbal art. Geelong: Deakin University Press.

Hatton, C., Emerson, E., Kirby, S. Kotwal, H., Baines, S., Hutchison, C. Dobson, K. \& Marks, B. (2010) Majority and Minority Ethnic Family Carers of Adults with Intellectual Disabilities: Perceptions of challenging behaviour and family impact. Journal of Applied Research in Intellectual Disabilities, 23(1), 63-74.

Henderson-Brooks, C. (2006). 'Words being its marker': a linguistic study of self as shifting state in three types of psychotherapeutic conversation. In Swain, E. (Ed.) Thresholds and Potentialities of Systemic Functional Linguistics: Multilingual, Multimodal and Other Specialised Discourses. Gorizia: University of Trieste, 229-267.

Hodge, N., \& Runswick-Cole, K. (2008). Problematising parent-professional partnerships in education. Disability \& Society, 23(6), 637-647.

Hubert, J. (2010). 'My heart is always where he is'. Perspectives of mothers of young people with severe intellectual disabilities and challenging behaviour living at home. British Journal of Learning Disabilities. 39, 216-224.

Jacobs, M., Marks Woolfson, L. \& Hunter, S. C. (2016). Attributions of Stability, Control and Responsibility: How Parents of Children with Intellectual Disabilities View their Child's Problematic Behaviour and Its Causes. Journal of Applied Research in Intellectual Disabilities 29(1): 58-70.

Karimi, N., Lukin, A, Moore, A.R. Walczak, A. \& Butow, P. (in press) Advanced cancer patients' construction of self during oncology consultation: a transitivity concordance analysis. Functional Linguistics. 
Keen, D. (2007) Parents, families and partnerships: Issues and considerations, International Journal of Disability, Development and Education, 54(3), 339349.

Lukin, A. (2013) The meanings of war: from lexis to context. Journal of Language and Politics, 12(3): 424-444.

Martin, J.R (2000) Close reading: functional linguistics as a tool for critical analysis. L. Unsworth (Ed.) Researching Language in Schools and Communities: functional linguistics approaches. London: Cassell. 275-303.

McConkey R. (2005). Fair shares? Supporting families caring for adult persons with intellectual disabilities. Journal of Intellectual Disability Research, 49, 600-612. McGill, P., Tennyson, A. \& Cooper, V. (2006). Parents Whose Children with Learning Disabilities and Challenging Behaviour Attend 52-week Residential Schools: Their Perceptions of Services Received and Expectations of the Future. The British Journal of Social Work, 36(4), 597-616.

McGill, P., Papachristoforou, E., \& Cooper, V. (2006) Support for family carers of children and young people with developmental disabilities and challenging behaviour. Childcare Health Development, 32(2),159-65.

McKenzie, K., Mayer, C., Whelan, K. J., McNall, A., Noone, S. \& Chaplin, J. (2017). The views of carers about support for their family member with an intellectual disability: With a focus on positive behavioural approaches. Health and Social Care in the Community, 26(1), 56-63.

Ng, J. \& Rhodes, P. (2018) Caring in Extremis: Why do parents of children with intellectual disabilities and severe challenging behaviour relinquish care. The Qualitative Report, 23(1), 146-157. 
Plant K.M. \& Sanders M.R. (2007). Predictors of care-giver stress in families of preschool-aged children with developmental disabilities. Journal of Intellectual Disability Research, 51, 109-24.

Read, J. (2000). Disability, the family, and society: Listening to mothers: Open University Press.

Storr, G. L. (2014). Parental experiences of caring for a child with intellectual disabilities: A UK perspective. Journal of Intellectual Disabilities, 18(2), 146158.

Thompson-Janes, E., Brice, S., McElroy, R., Abbott, J. \& Ball, J. (2014). Learning from the experts: a thematic analysis of parent's experiences of attending a therapeutic group for parents of children with learning disabilities and challenging behaviour. British Journal of Learning Disabilities, 44, 95-102.

Walmsley, J., Tilley, L., Dumbleton, S. \& Bardsley, J. (2017). The changing face of parent advocacy: a long view. Disability \& Society 32(9), 1366-1386.

Figure 1: Derivation of dataset: material process I-statements

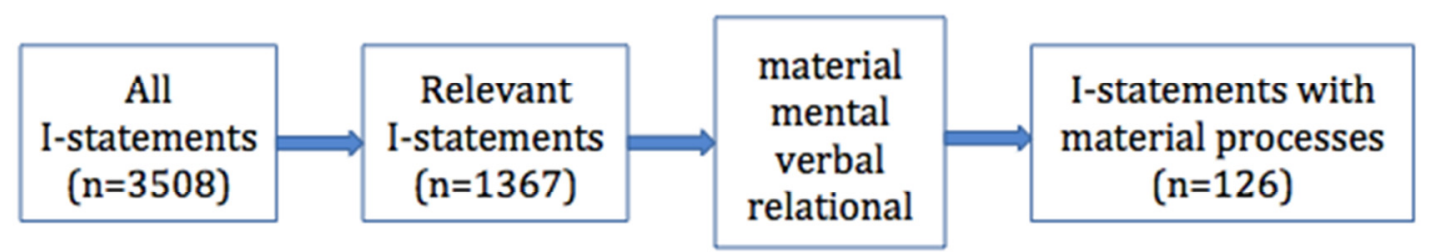

Figure 2: Types of 'material' activities parents do in relation to getting behaviour support and coping with their life 


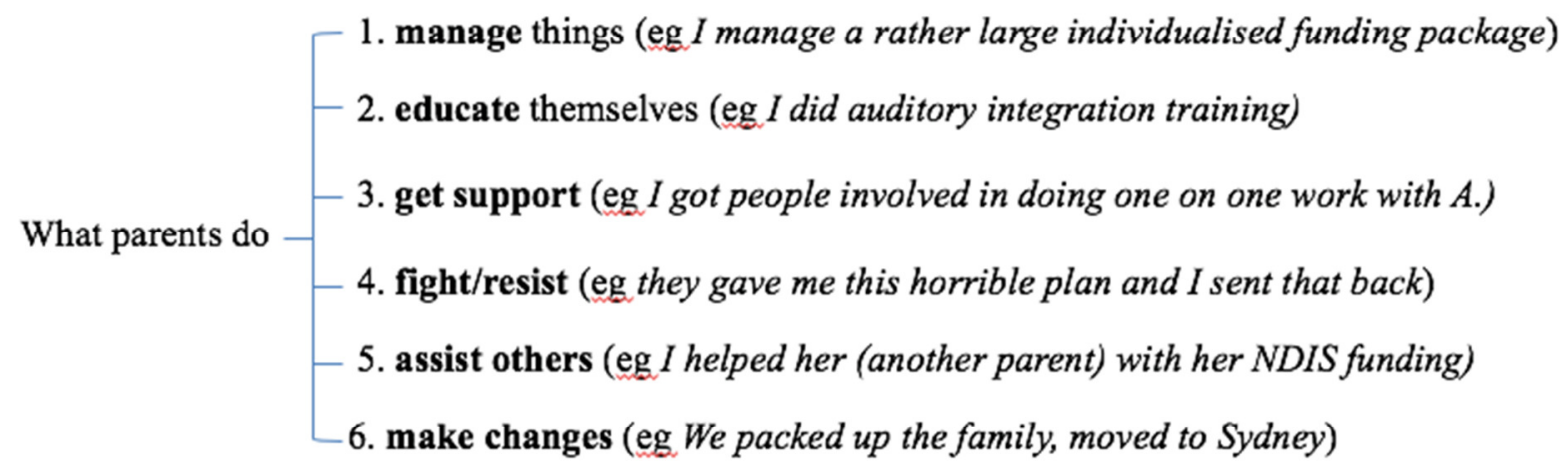

Table 1

\begin{tabular}{|l|l|l|}
\hline 1 & Management & 69 \\
\hline 2 & Education & 20 \\
\hline 3 & Support seeking & 11 \\
\hline 4 & Resistance & 9 \\
\hline 5 & Assistance & 6 \\
\hline 6 & Change & 6 \\
\hline 7 & Miscellaneous & 5 \\
\hline TOTAL & & 126 \\
\hline
\end{tabular}

Figure 3: Aspects of life parents spoke about managing

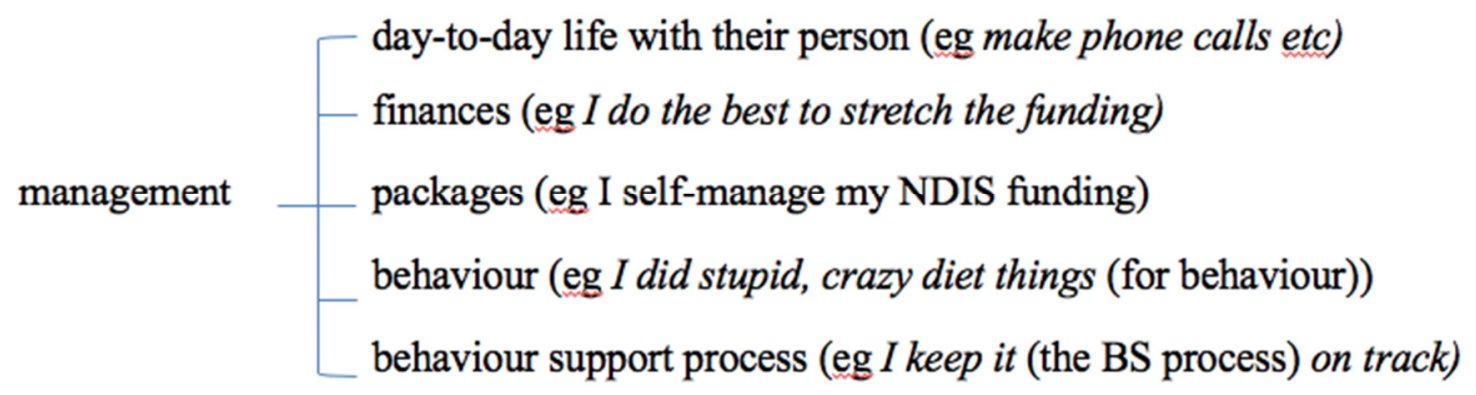

Figure 3.1: Areas in day-to-day life parents spoke about managing 


\begin{tabular}{|c|c|}
\hline \multirow{9}{*}{$\begin{array}{l}\text { managing } \\
\text { day-to-day } \\
\text { life }\end{array}$} & making phone calls \\
\hline & - organising and attending appointments \\
\hline & _dealing with agencies \\
\hline & interacting with many people, agencies and \\
\hline & organisations in both formal and informal networks \\
\hline & recruiting and interviewing support workers \\
\hline & admin \\
\hline & waiting \\
\hline & modifying the home environment \\
\hline
\end{tabular}

Figure 4: Parents' assistance to others

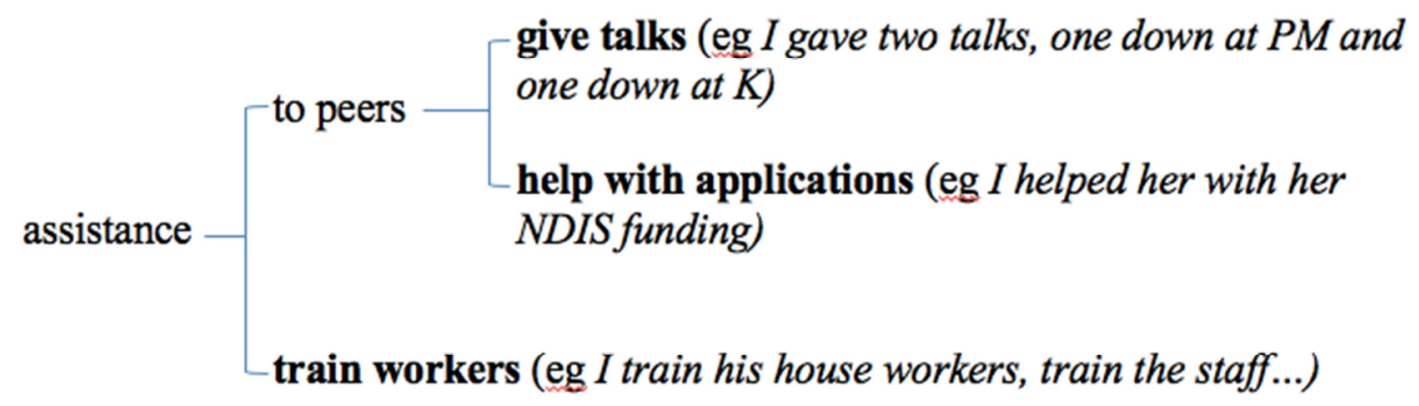

Figure 5: Changes parents made

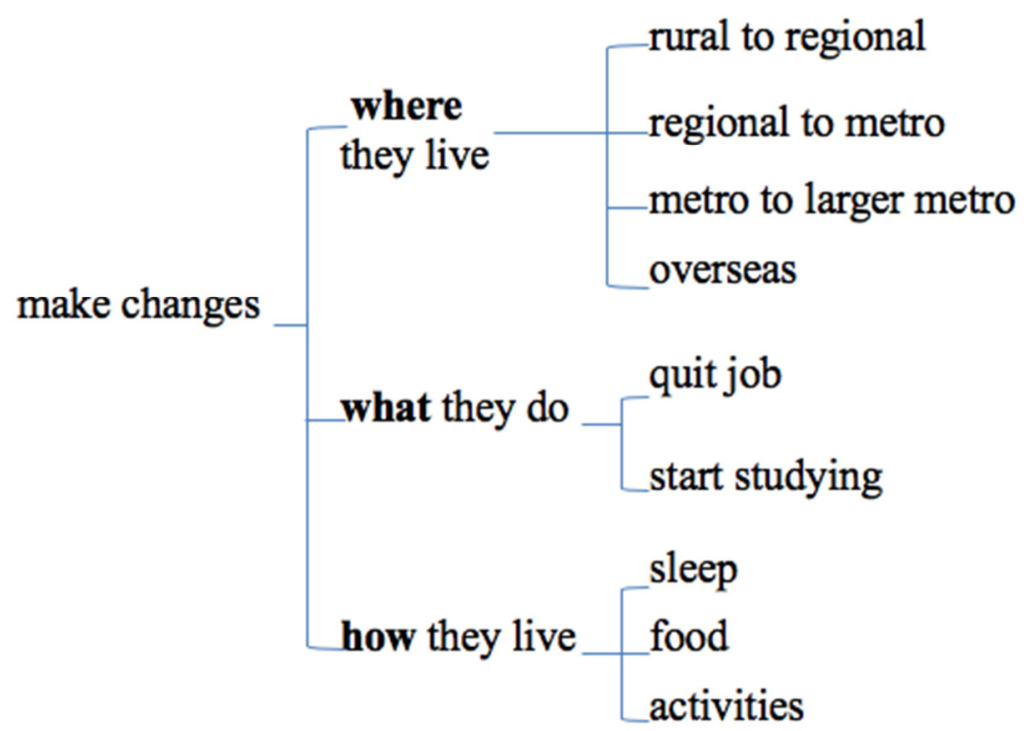

